\title{
Mini Review \\ Heart rate variability as important approach for assessment autonomic modulation
}

\author{
Maycon Jr Ferreira \\ Angelina Zanesco \\ Universidade Estadual Paulista “Julio de Mesquita Filho”, Rio Claro, SP, Brasil
}

\begin{abstract}
Alterations in the heart rate recovery and heart rate variability have been associated with greater risk of mortality and early prognosis of cardiac diseases. Thus, strategies for assessing autonomic nervous system and its modulation to the heart are crucial for preventing cardiovascular events in healthy subjects as well as in cardiac patients. In this review, an update of studies examining heart rate variability (HRV) and its use as indicator of cardiac autonomic modulation will be discussed. It will be described the indexes and methods of analysis and its applicability and the effects of exercise training on HRV and heart rate recovery in different population.
\end{abstract}

Keywords: autonomic nervous system, exercise, heart rate, vagal modulation

\section{Introduction}

\section{Cardiovascular system, autonomic nervous system and cardiac function}

The cardiovascular system is characterized by a complex interaction of several organ and tissues including heart and blood vessels and it is regulated by intrinsic and extrinsic mechanisms. The autonomic nervous system (ANS) provides rapid adjustments of the heart and blood vessels playing an important role on cardiovascular system regulation (Guyton \& Hall, 2006).

The heart is a muscular organ with a special excitatory and conduction specialized system able in generating rhythmic electrical impulses as well as to transmit these signals throughout the myocardium. Under normal conditions, the conduction process begins in a particular area of the heart, named atrial sinus node, which electrical property can generate the action potential that spreads quickly by specialized fibers to the heart resulting in contraction of entire cardiac muscle (Shaffer, McCraty, \& Zerr, 2014). In addition to this intrinsic mechanism that determines the basal cardiac rhythm, the ANS plays an important role in controlling heart function and vascular system through the sympathetic and parasympathetic fibers to the heart and sympathetic fibers to the vessels (Hainsworth, 1998). In the heart, norepinephrine released from autonomic sympathetic fibers produces positive inotropic and chronotropic responses acting through stimulation of $\beta$-adrenoceptors (Feldman, 1987). On the other hand, acetylcholine released from parasympathetic fibers produces negative inotropic and chronotropic responses through stimulation of muscarinic receptors (Dörje et al., 1991). Thus, the two branches of ANS, sympathetic and parasympathetic fibers, act in an opposite way providing a fine adjustment on the cardiac tissues in response to different stimuli and daily activities. In blood vessels, norepinephrine released from autonomic sympathetic fibers causes vasoconstriction response by activating $\alpha$-adrenergic receptors/IP3 signaling pathway. Thus, an unbalance between sympathetic and parasympathetic drive has been proposed as a potential mechanism in some cardiovascular diseases such as arterial hypertension, heart failure and myocardial infarct. On the other hand, it has been demonstrated that exercise training can improve the autonomic dysfunction in these pathological conditions (Carter \& Ray, 2015).

\section{Adrenergic and cholinergic receptors in the heart}

In the heart, the sympathetic endings are responsible for innervation of the entire organ, while parasympathetic nerve endings are present only in the sinoatrial node, atrial myocardium and atrioventricular node (Guyton \& Hall, 2006). At least three distinct subtypes of $\beta$-adrenoceptors have been described in cardiac tissue, namely $\beta_{1}, \beta_{2}$, and $\beta_{3}$ (Emorine et al., 1989; Kaumann \& Molenaar, 1997). The activation of $\beta$-adrenoceptors stimulate Gs-protein (stimulatory G-protein), which in turn, promotes activation of adenylyl cyclase, that catalyzes the conversion of adenosine triphosphate (ATP) to cyclic adenosine 3'5'-monophosphate (cAMP). The increment of cAMP levels activates protein kinase $\mathrm{A}$, which phosphorylates several proteins leading to an increase of intracellular $\mathrm{Ca}^{2+}$ concentration resulting in positive chronotropic and inotropic responses (Birnbaumer, 1990; Rodbell, 1980).

Acetylcholine released from parasympathetic fibers can stimulate two major types of receptor named nicotinic and muscarinic receptors. Muscarinic receptors belong to the class of $\mathrm{G}$ protein-coupled receptor and are widely distributed throughout the periphery and the central nervous system (Caulfield, 1993). Five subtypes of muscarinic cholinergic receptors have been detected by molecular cloning named $\mathrm{M}_{1}, \mathrm{M}_{2}, \mathrm{M}_{3}, \mathrm{M}_{4}$, and $\mathrm{M}_{5}$. In cardiac tissue, the stimulation of the subtype $\mathrm{M}_{2}$ muscarinic receptor by acetylcholine promotes an activation of a Gi protein causing inhibition of adenylyl cyclase and/or activation of receptor-operated $\mathrm{K}^{+}$channels leading to negative chronotropic and inotropic response (Kubo et al., 1986). 


\section{Cardiovascular system, autonomic nervous system and arterial baroreflex}

Arterial baroreceptors are stretch sensors that innervate adventitia of aortic arch and carotid sinuses. Increase in arterial blood pressure regulate arterial baroreceptors activity which, in turn, triggers a membrane depolarization by activating ion channels in the afferent fibers transmitting to the central nervous system. When arterial blood pressure is diminished this signaling activation is blunted. The main site of afferent fibers from arterial baroreceptors is the nucleus of the tractus solitarius (NTS). In the NTS, a complex neuronal network is activated (or deactivated) and a number of cellular effector systems modulates sympathetic or parasympathetic fibers (Guyton \& Hall, 2006). NTS is essential for arterial baroreceptor reflex function (Figure 1). It has been well documented that arterial baroreflex dysfunction is clinically relevant, particularly, alterations in the heart rate or its variability have been associated with greater risk of mortality and cardiac diseases (Parati, Di Rienzo, \& Mancia, 2001).

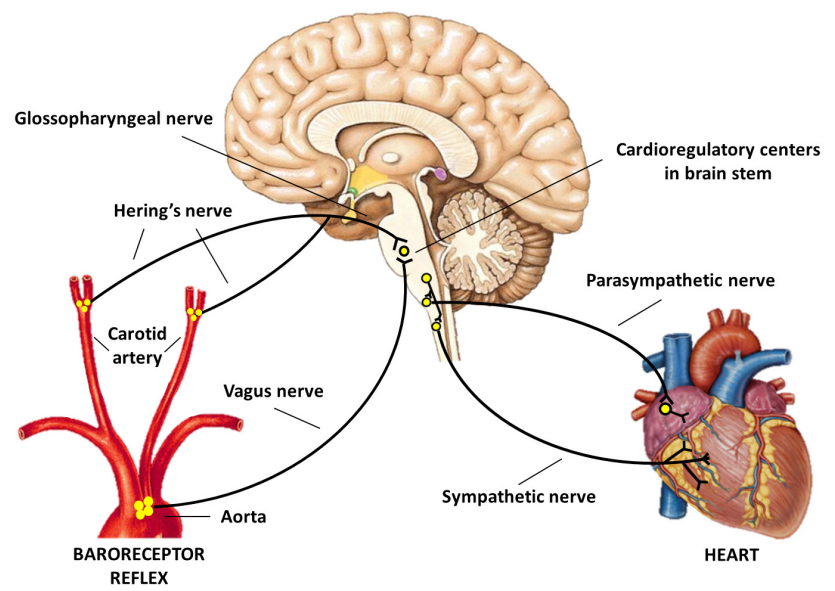

Figure 1. Overview the neural communication pathways between baroreceptor reflex and control of heart rate by autonomic nervous system.

\section{Heart rate variability assessment}

The assessment of HRV has been considered as an important non-invasive method able in promoting indirect information about cardiac autonomic modulation. This method consists in analyzing the fluctuations in interval between successive heartbeats, defined by the distance between two $\mathrm{R}$ waves (R-R interval), which reflect the autonomic control, through the sympathetic and parasympathetic, influences on the heart (Lahiri, Kannankeril, \& Goldberger, 2008) (Figure 2). It has demonstrated that the increase in the vagal efferent modulation is characterized by increasing in the HRV, whereas sympathetic stimulation diminishes the HRV which, in turn, has been associated with an increased risk of cardiovascular events and death in healthy patients (Tsuji et al., 1994, 1996). Indeed, many researchers have focused their studies on analysis of HRV patterns obtained under different physiological conditions in an attempt to evaluate the autonomic cardiovascular control in healthy individuals as well as the integrity of ANS in patients with cardiovascular diseases (Singh et al., 1998). Moreover, this analysis has been used, in order, to examine the acute or chronic responses promoted by physical exercise on the cardiovascular system (Anaruma, Ferreira, Sponton, Delbin, \& Zanesco, 2015; Grant, Viljoen, Janse van Rensburg, \& Wood, 2012; Jurca, Church, Morss, Jordan, \& Earnest, 2004)

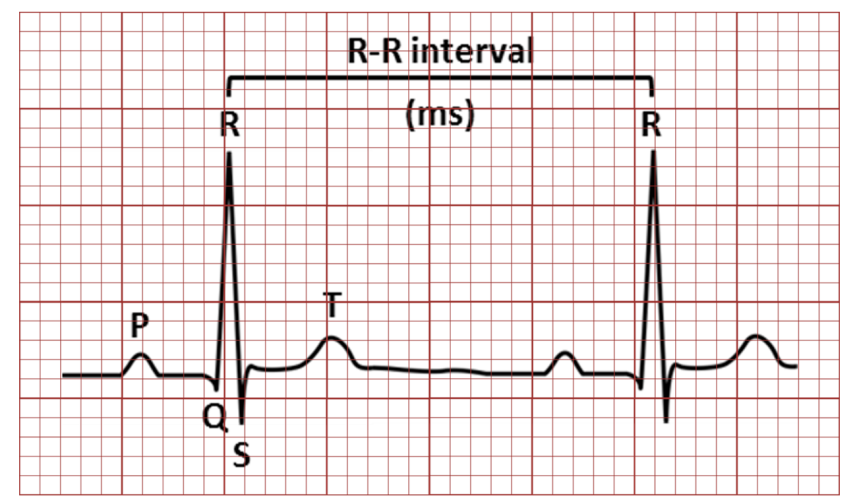

Figure 2. ECG tracing in healthy individual

Cardiac rhythmicity and its relationship with the various physiological mechanisms have been historically investigated. During centuries, researchers sought in monitoring the patterns of sounds and rhythms cardiac and to examine that factors such as age, presence of diseases and physiological status would be associated with changes in rhythmic patterns of the heart (Berntson et al., 1997).

The first historical accounts documented about HRV are assigned to the finding of Hales in 1733 using a horse. He was the first to verify a relationship between change in blood pressure levels and beat-to-beat interval with the respiratory cycle. In the following century, through the creation of the apparatus termed "kymograph" able to graphically record variations in movement, Ludwig in 1847 reported what had come to be later known as respiratory sinus arrhythmia (RSA). In their study using dog, he found that the breathing pattern was able to promote fluctuations in amplitude and timing of the arterial pressure waves, so that the inspiration promotes an acceleration of the pulse while the expiration lead the opposite effect. In addition, Donders in 1868 suggested that the activation of the vagus nerve was responsible for the changes in the duration of the cardiac cycle associated with breathing, fact that has been demonstrated in the following years. Several other studies have been conducted sought to investigate the relationship between sympathetic and parasympathetic efferent on fluctuations in arterial pressure waves and heart rate, recognizing the HRV as an important physiologic measure (Berntson et al., 1997).

It was in the mid 1960s that the physiological and clinical significance of HRV was first demonstrated showing that fetal distress was preceded by a reduction in the interval between heartbeats before any significant change in heart rate (Hon \& Lee; 1965). During the 1970s, it was demonstrated for the first time the association between reduced HRV and increased risk of mortality after acute myocardial infarction (Wolf, Varigos, Hunt \& Sloman, 1978). In an early study, using the short-term changes 
in R-R interval an association between autonomic neuropathy and diabetic state was described (Ewing, Martyn, Young, \& Clarke, 1985). With the advancement of technology combined with application of new processing techniques and analysis, several new studies were carried out allowing a greater understanding of the heart rate and their interaction with the ANS. On the other hand, the high complexity involving the direct measurement techniques of cardiac autonomic activity, mainly because the assessment of vagal activity not be performed in humans (Tan, 2013) further contributed to the assessment of HRV was considered an important variable in clinical practice (Shaffer et al., 2014).

\section{Methods and techniques for HRV analysis}

The HRV has been considered as a variable that allows estimation of cardiac autonomic modulation. Fluctuations in the R-R intervals may be quantified by numerous techniques evaluation capable of providing indices that reflect the ANS modulation into the heart. With the objective to standardize the terms and measurement methods in both basic and in clinical studies, members of the European Society of Cardiology and the North American Society of Pacing and Electrophysiology created a Task Force (Task Force, 1996).

Currently, HRV analysis can be performed using linear methods, which are divided in the time domain and the frequency domain, and also using non-linear methods. In the linear analysis in the time domain, which is considered as the simplest measure of the HRV, the indices are derived from the measurement of intervals between normal beats (normal-to-normal) successive in a series of continuous time that can be evaluated by statistical or geometric patterns (Bilchick \& Berger, 2006; Task Force, 1996). The indices obtained commonly used include the standard deviation of all normal-to-normal (NN) intervals (SDNN), i.e., the square root of the variance, which reflects the total variability during the recorder period. Characterized as the most widely used index in the time domain, the calculation of SDNN requires attention because the presence of ectopic beats and artifacts as well as the duration of registration can directly influence the measurements (Kleiger, Stein, \& Bigger, 2005). Besides this, other variables calculated during the registration period include the standard deviation of the averages of $\mathrm{NN}$ intervals calculated in all 5 minutes segments of the entire recording (SDANN), which measures changes in the long-term, and the mean of the standard deviation of the $\mathrm{NN}$ intervals for all 5 minutes (SDNN index) and reflect the average of changes occurring at intervals within the time of 5 minutes (Task Force, 1996). The analysis in the time domain further provides other related measures which are derived from the difference between the R-R intervals, including the square root of the mean of the sum of the squares of differences between successive NN intervals (RMSSD), the number of pairs pf adjacent NN intervals with a difference of duration longer than $50 \mathrm{~ms}$ in the registration period (NN50) and the percentage of successive NN intervals with a difference of duration longer than $50 \mathrm{~ms}$ (pNN50). These indices are obtained by the difference between successive regular intervals aiming to detect high frequency oscillations and to provide information on parasympathetic autonomic modulation (Kleiger et al., 2005; Pumprla, Howorka, Groves, Chester, \& Nolan, 2002).

The geometric analysis method consists in further analysis of HRV in the time domain, where in the R-R intervals are converted graphically in geometric patterns (Task Force, 1996). The triangular index HRV is calculated using the number of all $\mathrm{NN}$ intervals divided by the maximum distribution density. The reduction of this index has been associated with an increased mortality (Ewing et al., 1985). Another technique is the Lorenz plot (also known as a Poincaré plot), where each beat is plotted in association with the next beat, providing graphical information and dispersion of the variation in the time series. This analysis can be performed both quantitatively and qualitatively (Billman, 2011).

The linear method in the frequency domain (spectral analysis) has been widely used since its introduction in the 1960s as another technique for the investigation of HRV. Unlike the time domain, this technique decomposes the total variability of the signal in specific components that operate in different frequency bands, allowing identification (Shaffer et al., 2014). The calculation of the power of spectral density (PDS) can be done through the fast Fourier transform techniques (FFT) or by autoregressive (AR) model. Regardless of the technique used, as short-time records (2-5 minutes) it is possible to obtain the components of very low frequency $(\mathrm{VLF})(<0.04 \mathrm{~Hz})$, low frequency $(\mathrm{LF})(0.04-0.15 \mathrm{~Hz})$ and high frequency $(\mathrm{HF})(0.15-0.4 \mathrm{~Hz})$, while in the analysis over 24 hours a fourth peak frequency, represented as ultra low frequency (ULF) $(0.003-0.04 \mathrm{~Hz})$ can also be obtained (Billman, 2011; Task Force, 1996).

The HF component has been widely emphasized as an index that reflects the vagal modulation, whereas the LF component reflects an interaction between sympathetic and parasympathetic (Kleiger et al., 2005). On the other hand, experimental data suggest that the rhythm pattern of VLF is intrinsically generated by the heart and that its oscillation is modulated by sympathetic nerve endings (McCraty \& Shaffer, 2015). In addition, the calculation of LF and HF (LF/HF) has been used historically as a measure involving the sympathetic/parasympathetic balance (Malliani, Pagani, Lombardi, \& Cerutti, 1991; Pagani et al., 1986). Nevertheless, recent studies suggest that this measure can not be an accurate measure of this balance (Billman, 2013).

The evaluation of the HRV from the linear methods can be performed from records with duration of 2, 5 and 15 minutes (short-time) and over 24 hours (long-time). Although it is also used for short-term analysis, the indices obtained in the time domain have been commonly used for long-term records to promote a better interpretation of the results because of the the instability of the heart rate over time. On the other hand, short records are preferably interpreted from the frequency domain indices (Task Force, 1996). The presence of noise, trends, ectopic beats and artifacts has been considered as the main problems found in the records of the HRV, which can directly affect the quality of HRV analysis, requiring the signal correction (Huikuri et al., 1999). 


\section{$H R V$ and exercise}

HRV has been frequently used to assess the modulation of the autonomic nervous system on the heart during and immediately after exercise, as well as the adaptations induced by long-term training (Krieger et al., 1998).

Evidence suggests that physical exercise promotes an improvement in the cardiac autonomic regulation, characterized by an increase in the R-R interval and increased vagal modulation (Sandercock, Bromley, \& Brodie, 2005). A higher HRV in trained individuals compared with untrained individuals has indeed been quite evident.

In athletes, it has been largely demonstrated that the indexes that reflect the cardiac vagal modulation are markedly increased, indicating that physical training positively affects the vagal tone and that this could contribute to lower heart rate observed at rest in this population (Aubert et al., 1996; Bonaduce et al., 1998; Goldsmith, Bigger, Steinman, \& Fleiss, 1992). In addition, evidence suggests that lower heart rate at rest in athletes is also due to intrinsic adaptations in cardiac signal conduction system (Shin, Minamitani, Onishi, Yamazaki, \& Lee, 1997).

The HRV indices have also been used to evaluate the influence of different levels of aerobic capacity on the autonomic modulation. No differences in autonomic modulation evaluated by HRV were found in healthy individuals at different levels of aerobic capacity or physical activity (Dutra et al., 2013; Melanson, 2000), showing no dose-dependent relationship with the aerobic capacity. Furthermore, other studies suggest that moderate volume of aerobic exercise is sufficient to induce beneficial effects on the cardiovascular autonomic system in healthy subjects (Earnest, Blair, \& Church, 2012; Tulppo et al., 2003).

Interestingly, contradictory results have been observed evaluating the HRV in elderly (70 and 80 years) and middle-aged population where no changes were observed through HRV index in the frequency domain after exercise training (Loimaala, Huikuri, Oja, Pasanen, \& Vuori, 2000; Perini, Fisher, Veicsteinas, \& Pendergast, 2002).

The HRV indices were also been used to assess autonomic modulation in response to exercise in patients under different pathological conditions. Regarding cardiovascular diseases, studies have shown that physical training promotes increased in the HRV in hypertensive (Cozza et al., 2012), diabetics (Zoppini et al., 2007) and coronary artery disease patients (Iellamo, Legramante, Massaro, Raimondi, \& Galante, 2000).

The exercise training has also been able to change the HRV in favor of a increase autonomic vagal modulation in postmenopausal women (Earnest et al., 2012; Jurca et al., 2004).

Finally, the physiological responses of HRV after a bout of exercise are clinically relevant and it has been used as an important approach to detect early symptoms of autonomic dysfunction in patients with diabetes or other cardio metabolic diseases. Indeed, heart rate recovery measurement after exercise test is considered crucial to examine the sympatho-vagal balance since during exercise sympathetic drive is increased while a decrease in parasympathetic activity is withdrawal or diminished, whereas in the recovery period changes in autonomic tone are observed characterized by sympathetic withdrawal and parasympathetic reactivation with gradual return of heart rate to resting level. Thus, clinical studies have proposed that a decrease in heart rate from peak exercise to 1 min into recovery of $<12$ beats/min or less is defined as abnormal heart rate recovery and a predictor of mortality indicating impairment of the integrity of parasympathetic tone (Cole, Blackstone, Pashkow, Snader, \& Lauer, 1999). A recent study from our laboratory showed a lower SDNN index, which indicates lower vagal modulation, during recovery time in type 1 diabetic patients suggesting an autonomic imbalance even though the patients did not present an overt cardiovascular disease (Anaruma et al., 2015). Therefore, the analysis of HRV and heart rate recovery immediately after exercise is extremely useful providing valuable information about the autonomic control as well as its integrity.

\section{Final considerations}

Interest in the study of HRV has increased significantly since the first reports of its clinical relevance and its association with an increased risk of mortality after acute myocardial infarction. In an attempt to understand the role of the autonomic nervous system on the heart rate, assessment of the sympathetic and parasympathetic modulation is crucial in exercise science applied to sports and health. The use of spectral analysis of HRV has not shown satisfactory results in the evaluation of changes in autonomic regulation during exercise, however it has been a feasible methodology to examine the influence of both sympathetic and parasympathetic nerves into the heart rate mainly during recovery period after exercise test . Moreover, adaptations of the autonomic nervous system induced by physical training are not yet fully understood. Although strong evidence has shown an improvement in autonomic modulation by increasing the HRV after long-term training, controversial results exist.

In conclusion, the HRV has proven to be a useful method non-invasive and practical for the quantitative assessment of the acute and chronic effects of exercise on cardiac autonomic modulation in humans, mainly parasympathetic tone influence. HRV should be a complementary measurement in cardiovascular assessments in different populations; however, it is necessary large scale studies to get more conclusive data.

\section{REFERENCES}

Anaruma, C.P., Ferreira, M.J., Sponton, C.H.G., Delbin, M.A., \& Zanesco, A. (2015). Heart rate variability and plasma biomarkers in patients with type 1 diabetes mellitus : Effect of a bout of aerobic exercise. Diabetes Research and Clinical Practice, 111, 19-27. http://doi.org/10.1016/j.diabres.2015.10.025

Aubert, A.E., Ramaekers, D., Cuche, Y., Lysens, R., Ector, H., \& Van de Werf, F. (1996). Effect of long term physical training on heart rate variability. Computers in Cardiology, 16, 17-20. Retrieved from $\mathrm{http}$ ///ieeexplore.ieee.org/xpls/abs_all.jsp?arnumber=542462

Berntson, G.G., Bigger, J.T.J., Eckeberg, D.L., Grossman, P., Kaufmann, P.G., Malik, M., ... van der Molen, M. W. (1997). Heart rate variability: Origins, methods, and interpretative caveats. Psychophysiology, 
34(6), 623-648. http://doi.org/10.1111/j.1469-8986.1997. tb02140.x

Bilchick, K.C., \& Berger, R.D. (2006). Heart rate variability. Journal of Cardiovascular Electrophysiology, 17(6), 691-694. http://doi. org/10.1111/j.1540-8167.2006.00501.x

Billman, G.E. (2011). Heart rate variability - A historical perspective. Frontiers in Physiology, 2, 1-13. http://doi.org/10.3389/ fphys.2011.00086

Billman, G.E. (2013). The LF/HF ratio does not accurately measure cardiac sympatho-vagal balance. Frontiers in Physiology, 4, 1-5. http://doi.org/10.3389/fphys.2013.00026

Birnbaumer, L. (1990). G proteins in signal transduction. Annual Review of Pharmacology and Toxicology, 30, 675-705. http://doi. org/10.1146/annurev.pa.30.040190.003331

Bonaduce, D., Petretta, M., Cavallaro, V., Apicella, C., Ianniciello, A., Romano, M., ... Marciano, F. (1998). Intensive training and cardiac autonomic in high level athletes. Medicine and Science in Sports and Exercise, 30(5), 691-696. http://doi.org/10.1017/ CBO9781107415324.004

Carter, J.R., \& Ray, C.A. (2015). Sympathetic neural adaptations to exercise training in humans. Autonomic Neuroscience: Basic and Clinical, 188, 36-43. http://doi.org/10.1016/j. autneu.2014.10.020

Caulfield, M.P. (1993). Muscarinic receptors--characterization, coupling and function. Pharmacology \& Therapeutics, 58(3), 319-379. http://doi.org/10.1016/0163-7258(93)90027-B

Cole, C.R., Blackstone, E.H., Pashkow, F.J., Snader, C.E., \& Lauer, M.S. (1999). Heart-rate recovery immediately after exercise as a predictor of mortality. The New England Journal of Medicine, 341(18), 1351-1357. http://doi.org/10.1056/NEJM199910283411804

Cozza, I.C., Di Sacco, T.H.R., Mazon, J.H., Salgado, M.C.O., Dutra, S.G.V, Cesarino, E.J., \& Souza, H.C.D. (2012). Physical exercise improves cardiac autonomic modulation in hypertensive patients independently of angiotensin-converting enzyme inhibitor treatment. Hypertension Research, 35(1), 82-7. http://doi.org/10.1038/ hr.2011.162

Donders, F.C. (1868). Zur physiologie des nervus vagus. Pflügers Archiv - European Journal of Physiology, 1, 331-361.

Dörje, F., Wess, J., Lambrecht, G., Tacke, R., Mutschler, E., \& Brann, M.R. (1991). Antagonist binding profiles of five cloned human muscarinic receptor subtypes. The Journal of Pharmacology and Experimental Therapeutics, 256(2), 727-733.

Dutra, S.G.V, Pereira, A.P.M., Tezini, G.C.S.V, Mazon, J.H., MartinsPinge, M.C., \& Souza, H.C.D. (2013). Cardiac autonomic modulation is determined by gender and is independent of aerobic physical capacity in healthy subjects. PLOS ONE, 8(10), 1-9. http://doi. org/10.1371/journal.pone.0077092

Earnest, C.P., Blair, S.N., \& Church, T.S. (2012). Heart rate variability and exercise in aging women. Journal of Women's Health, 21(3), 334-339. http://doi.org/10.1089/jwh.2011.2932

Emorine, L.J., Marullo, S., Briend-Sutren, M.M., Patey, G., Tate, K., DelavierKlutchko, C., \& Strosberg, A.D. (1989). Molecular characterization of the human beta3 -adrenergic receptor. Science, 245(1986), 1118-1121.

Ewing, D.J., Martyn, C.N., Young, R.J., \& Clarke, B.F. (1985). The value of cardiovascular autonomic function tests: 10 years experience in diabetes. Diabetes Care, 8(5), 491-498. http://doi. $\operatorname{org} / 10.2337 /$ diacare.8.5.491
Feldman, R.D. (1987). ß-Adrenergic receptor alterations in hypertension-physiological and molecular correlates. Canadian Journal of Physiology and Pharmacology, 65(8), 1666-1672. http://doi. org/10.1139/y87-261

Goldsmith, R.L., Bigger, J.T.J., Steinman, R.C., \& Fleiss, J.L. (1992). Comparison of 24-hour parasympathetic activity in endurance-trained and untrained young men. Journal of the American College of Cardiology, 20(3), 552-558. http://doi. org/10.1016/0735-1097(92)90007-A

Grant, C.C., Viljoen, M., Janse van Rensburg, D.C., \& Wood, P.S. (2012). Heart rate variability assessment of the effect of physical training on autonomic cardiac control. Annals of Noninvasive Electrocardiology, 17(3), 219-229. http://doi. org/10.1111/j.1542-474X.2012.00511.x

Guyton, A.C., \& Hall, J.E. (2006). Tratado de Fisiologia Médica. 11 edição. Rio de Janeiro, RJ: Elsevier Editora.

Hainsworth, R. (1998). Physiology of the cardiac autonomic system. In: M. Malik (Ed.), Clinical Guide to Cardiac Autonomic Tests (3-28). Boston, MA: Springer Netherlands.

Hales, S. (1733). Statical essays: Concerning haemastaticks; Or, an account of some hydraulick and hydrostatical experiments made on the blood and blood vessels of animals. London: Published by W. Innys and R.Manby.

Hon, H.E., \& Lee, S.T. (1965). Electronic evaluations of the fetal heart rate patterns preceding fetal death, further observations. American Journal of Obstetrics \& Gynecology, 87, 814-826.

Huikuri, H.V, Mäkikallio, T., Airaksinen, K.E.J., Mitrani, R., Castellanos, A., \& Myerburg, R.J. (1999). Measurement of heart rate variability: A clinical tool or a research toy? Journal of the American College of Cardiology, 34(7), 1878-1883. http://doi. org/10.1016/S0735-1097(99)00468-4

Iellamo, F., Legramante, J.M., Massaro, M.M., Raimondi, G., \& Galante, A. (2000). Effects of a residential exercise training on baroreflex sensitivity and heart rate variability in patients with coronary artery disease: A randomized, controlled study. Circulation, 102(21), 2588-2592. http://doi.org/10.1161/01.CIR.102.21.2588

Jurca, R., Church, T.S., Morss, G.M., Jordan, A.N., \& Earnest, C.P. (2004). Eight weeks of moderate-intensity exercise training increases heart rate variability in sedentary postmenopausal women. American Heart Journal, 147(5), 828.e8-828.e15. http://doi. org/10.1016/j.ahj.2003.10.024

Kaumann, A.J., \& Molenaar, P. (1997). Modulation of human cardiac function through $4 \mathrm{~B}$-adrenoceptor populations. NaunynSchmiedeberg's Archives of Pharmacology, 355(6), 667-681. http:// doi.org/10.1007/PL00004999

Kleiger, R.E., Stein, P.K., \& Bigger, J.T.J. (2005). Heart rate variability: Measurement and clinical utility. Annals of Noninvasive Electrocardiology, 10(1), 88-101. http://doi. org/10.1111/j.1542-474X.2005.10101.X

Krieger, E.M., Brum, P.C., \& Negrão, C.E. (1998). Role of arterial baroreceptor function on cardiovascular adjustments to acute and chronic dynamic exercise. Biological Research, 31, 273-279.

Kubo, T., Fukuda, K., Mikami, A., Maeda, A., Takahashi, H., Mishina, M., ... Numa, S. (1986). Cloning, sequencing and expression of complementary DNA encoding the muscarinic acetylcholine receptor. Nature, 323(2), 411-416. http://doi. org/10.1038/323411a0 
Lahiri, M.K., Kannankeril, P.J., \& Goldberger, J.J. (2008). Assessment of autonomic function in cardiovascular disease physiological basis and prognostic implications. Journal of the American College of Cardiology, 51(18), 1725-1733. http://doi.org/10.1016/j.jacc.2008.01.038

Loimaala, A., Huikuri, H., Oja, P., Pasanen, M., \& Vuori, I. (2000). Controlled 5-mo aerobic training improves heart rate but not heart rate variability or baroreflex sensitivity. Journal of Applied Physiology, 89(5), 1825-1829.

Ludwig, C.F.W. (1847). Beitrage zur Kenntniss des Einflusses der Respriations bewegungen auf den Blutlauf im Aortensysteme. Archiv für Anatomie und Physiologie, 13, 242-3027.

Malliani, A., Pagani, M., Lombardi, F., \& Cerutti, S. (1991). Cardiovascular neural regulation explored in the frequency domain. Circulation, 84(2), 482-492. http://doi.org/10.1161/01. CIR.84.2.482

McCraty, R., \& Shaffer, F. (2015). Heart rate variability: New perspectives on physiological mechanisms, assessment of self-regulatory capacity, and Health risk. Global Advances in Health and Medicine, 4(1), 45-61. http://doi.org/10.7453/gahmj.2014.073

Melanson, E.L. (2000). Resting heart rate variability in men varying in habitual physical activity. Medicine and Science in Sports and Exercise, 32(11), 1894-1901. http://doi. org/10.1097/00005768-199605001-00971

Pagani, M., Lombardi, F., Guzzetti, S., Rimoldi, O., Furlan, R., Pizzinelli, P., ... Malliani, A. (1986). Power spectral analysis of heart rate and arterial pressure variabilities as a marker of sympatho-vagal interaction in man and conscious dog. Circulation Research, 59(2), 178-193. http://doi.org/10.1161/01.RES.59.2.178

Parati, G., Di Rienzo, M., \& Mancia, G. (2001). Dynamic modulation of baroreflex sensitivity in health and disease. Annals of the New York Academy of Sciences, 940, 469-87. http://doi. org/10.1111/j.1749-6632.2001.tb03699.x

Perini, R., Fisher, N., Veicsteinas, A., \& Pendergast, D.R. (2002). Aerobic training and cardiovascular responses at rest and during exercise in older men and women. Medicine and Science in Sports and Exercise, 34(4), 700-708. http://doi. org/10.1097/00005768-200204000-00022

Pumprla, J., Howorka, K., Groves, D., Chester, M., \& Nolan, J. (2002). Functional assessment of heart rate variability: Physiological basis and practical applications. International Journal of Cardiology, 84(1), 1-14. http://doi.org/10.1016/S0167-5273(02)00057-8

Rodbell, M. (1980). The role of hormone receptors and GTP-regulatory proteins in membrane transduction. Nature, 284(5751), 17-22. http://doi.org/10.1038/284017a0

Sandercock, G.R.H., Bromley, P.D., \& Brodie, D.A. (2005). Effects of exercise on heart rate variability: Inferences from meta-analysis. Medicine and Science in Sports and Exercise, 37(3), 433-439. http://doi.org/10.1249/01.MSS.0000155388.39002.9D

Shaffer, F., McCraty, R., \& Zerr, C.L. (2014). A healthy heart is not a metronome: An integrative review of the heart's anatomy and heart rate variability. Frontiers in Psychology, 5(1040), 1-19. http://doi. org/10.3389/fpsyg.2014.01040

Shin, K., Minamitani, H., Onishi, S., Yamazaki, H., \& Lee, M. (1997). Autonomic differences between athletes and nonathletes: Spectral analysis approach. Medicine and Science in Sports and Exercise, 29(11), 1482-1490. http://doi.org/10.1017/ CBO9781107415324.004
Singh, J.P., Larson, M.G., Tsuji, H., Evans, J.C., O’Donnell, C.J., \& Levy, D. (1998). Reduced heart rate variability and new-onset hypertension: Insights into pathogenesis of hypertension: the Framingham Heart Study. Hypertension, 32(2), 293-297. http:// doi.org/10.1161/01.HYP.32.2.293

Tan, C.O. (2013). Heart rate variability: Are there complex patterns. Frontiers in Physiology, 4(165), 1-3. http://doi.org/10.3389/ fphys.2013.00165

Task Force. (1996). Heart rate variability: Standards of measurement, physiological interpretation, and clinical use. Task Force of the European Society of Cardiology and the North American Society of Pacing and Eletrophysiology. European Heart Journal, 17(3), 354-381.

Tsuji, H., Larson, M.G., Venditti, F.J., Manders, E.S., Evans, J.C., Feldman, C.L., \& Levy, D. (1996). Impact of reduced heart rate variability on risk for cardiac events. The Framingham Heart Study. Circulation, 94(11), 2850-2855. http://doi.org/10.1161/01. CIR.94.11.2850

Tsuji, H., Venditti, F.J., Manders, E.S., Evans, J.C., Larson, M.G., Feldman, C.L., \& Levy, D. (1994). Reduced heart rate variability and mortalit risk in an elderly cohort. The Framingham Heart Study. Circulation, 90(2), 878-883. http://doi.org/10.1161/01.CIR.90.2.878

Tulppo, M.P., Hautala, A.J., Mäkikallio, T.H., Laukkanen, R.T., Nissilä, S., Hughson, R.L., \& Huikuri, H.V. (2003). Effects of aerobic training on heart rate dynamics in sedentary subjects. Journal of Applied Physiology, 95(1), 364-372. http://doi.org/10.1152/ japplphysiol.00751.2002

Wolf, M.M., Varigos, G.A., Hunt, D., and Sloman, J. G. (1978). Sinus arrhythmia in acute myocardial infarction. The Medical Journal of Australia, 2(2), 52-53.

Zoppini, G., Cacciatori, V., Gemma, M.L., Moghetti, P., Targher, G., Zamboni, C., ... Muggeo, M. (2007). Effect of moderate aerobic exercise on sympatho-vagal balance in type 2 diabetic patients. Diabetic Medicine, 24(4), 370-376. http://doi. org/10.1111/j.1464-5491.2007.02076.x

\section{Autor's note}

Maycon Jr Ferreira and Angelina Zanesco are affiliated to the Laboratory of Cardiovascular Physiology and Exercise Science, Institute of Biosciences, UNESP, Rio Claro, SP, Brazil.

\section{Corresponding author}

Angelina Zanesco, Professor in Physiology, Institute of Biosciences, UNESP Av. 24A, 1515, Bela Vista, Rio Claro, SP, Brazil. Email: azanesco@rc.unesp.br; lina.co@hotmail.com

Manuscript received on February 16, 2016

Manuscript accepted on March 17, 2016

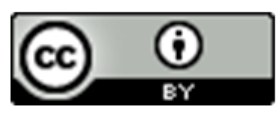

Motriz. The Journal of Physical Education. UNESP. Rio Claro, SP, Brazil - eISSN: 1980-6574 - under a license Creative Commons - Version 3.0 